\title{
Itaconic acid-modified layered double hydroxide as a novel adsorbent for effective removal of Congo red from aqueous solutions
}

Mohammad Dinari ( $\sim$ dinari@iut.ac.ir)

Isfahan University of Technology https://orcid.org/0000-0001-5291-7142

Shirin Shabani

Isfahan University of Technology

\section{Research Article}

Keywords: Cu-Ca-Al/NO3-based layered double hydroxide, Itaconic acid, Adsorption, Congo red, Kinetic and isotherm

Posted Date: March 22nd, 2021

DOI: https://doi.org/10.21203/rs.3.rs-345643/v1

License: (c) (i) This work is licensed under a Creative Commons Attribution 4.0 International License.

Read Full License 


\section{Itaconic acid-modified layered double hydroxide as a novel adsorbent}

\section{2 for effective removal of Congo red from aqueous solutions}

3

4

17

\section{Mohammad Dinari $^{* a}$ and Shirin Shabani ${ }^{b}$}

${ }^{a}$ Department of Chemistry, Isfahan University of Technology, Isfahan 84156-83111, Iran

${ }^{a}$ Chemistry group, Pardis College, Isfahan University of Technology, Isfahan 84156-83111, I.R. Iran

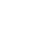

$2{ }^{*}$ Corresponding authors:

Mohammad Dinari, Department of Chemistry, Isfahan University of Technology, Isfahan

84156-83111, Iran

E-mail: dinari@iut.ac.ir 


\section{Abstract}

Herein, we report the synthesis of $\mathrm{Cu}-\mathrm{Ca}-\mathrm{Al} / \mathrm{NO}_{3}$-based layered double hydroxide through co-precipitation methodology. The prepared layered double hydroxide was then modified with itaconic acid. The physicochemical properties of the prepared materials were studied using Fourier transform-infrared spectroscopy, scanning electron microscopy, X-ray diffraction analysis, thermogravimetric analysis, and nitrogen adsorption/desorption technique. The prepared materials were then applied as novel adsorbents for the removal of Congo red as a model of an anionic dye from aqueous media. To reach maximum adsorption, the effect of parameters including sample solution $\mathrm{pH}$, adsorbent amount, contact time, and initial concentration of Congo red on the adsorption process was investigated. Kinetic studies were also conducted to study the mechanism of adsorption. In this regard, the kinetic models of pseudo-first-order, pseudo-second-order, Elovich, and intra-particle diffusion were studied. The results showed that the adsorption of Congo red onto $\mathrm{Cu}-\mathrm{Ca}-\mathrm{Al}-\mathrm{LDH}$ and LDH-ITA adsorbents followed the pseudo-second-order kinetic model. To evaluate the equilibrium adsorption data, different isotherms including Langmuir, Freundlich, and DubininRadushkevich were also applied. The data revealed that the Freundlich isotherm provided the best fit with the equilibrium data of both adsorbents. Maximum adsorption capacities of 81 and $84 \mathrm{mg} \mathrm{g}^{-1}$ were obtained using $\mathrm{Cu}-\mathrm{Ca}-\mathrm{Al}-\mathrm{LDH}$ and LDH-ITA adsorbents, respectively.

Keywords: $\mathrm{Cu}-\mathrm{Ca}-\mathrm{Al} / \mathrm{NO}_{3}$-based layered double hydroxide; Itaconic acid; Adsorption; Congo red; Kinetic and isotherm 


\section{Introduction}

As a growing trend, nanotechnology has attracted huge interest among scientists in various scientific fields such as catalysis [1-3], energy conversion and storage [4], sample preparation [5-8], and adsorption [9-15]. The great interest in the field of nanotechnology arises from the extraordinary physical, chemical, thermal, and mechanical characteristics of nanomaterials in comparison with large-size particles. In general, nano-sized materials exhibited high specific surface area, tailorable structure, thermal stability, high chemical and mechanical resistance, and easiness in functionalization. As a subgroup of inorganic layered nanomaterials, layered double hydroxides (LDHs) are ionic lamellar mixed hydroxides that consisted of positively charged main layers and an interlayer region with chargecompensating anions undergoing anion-exchange chemistry [16, 17]. They are generally demonstrated with a stoichiometry of $\left[\mathrm{M}_{1-\mathrm{x}}^{2+} \mathrm{M}_{\mathrm{x}}^{3+}(\mathrm{OH})_{2}\right]^{\mathrm{x}+}\left(\mathrm{A}^{\mathrm{n}-}\right)_{\mathrm{x} / \mathrm{n}} \cdot \mathrm{mH}_{2} \mathrm{O}[18,19]$. In this formula, $\mathrm{M}^{2+}$ and $\mathrm{M}^{3+}$ represent divalent and trivalent metals of the layers, respectively, and $\mathrm{A}^{\mathrm{n}-}$ is charge balancing anion in the interlayer region which can be readily replaced. Owing to their fantastic properties, nowadays LDHs with different compositions have received remarkable attention from academia and industry. They are exhibited important properties such as ion exchange capability, acid-base properties, and adsorption capacity. They are also low-cost materials and their properties can be easily tailored. The use of these materials in drug delivery [20], catalysis [21], energy conversion and storage [22], environmental remediation $[23,24]$, and sample preparation $[25,26]$ have been reported.

Despite the unique characteristics of LDHs, various functionalization strategies have been reported for the modification of LDHs to increase their performance and applications. Considering the surface properties of LDHs, they are easily agglomerated, usually incompatible with organic substances, and have low efficiency for specific applications. LDHs functionalization can drastically improve their performance and properties. Until now, 
various functionalization strategies have been used for the modification of LDHs. Some common functionalization strategies included intercalation, hybrid assembly, surface modification, size and morphology regulation, layer composition tuning, and defect introduction which are discussed in detail in a reported review by Laipan et al [27].

As an important environmental concern in both developing and industrial countries, the lack of clean water due to the disposal of various toxic compounds into the environment caused drastic concerns about the creature's health. As an unpleasant result of the industrialization process, water pollution is an international problem, and nowadays scientists, and policymakers are beginning to take more notice of this vital problem to find a suitable solution. Among the well-known pollutants, synthetic organic dyes are one of the important groups of water pollutants. The release of these contaminants is an increasing and serious global challenge from the environmental point of view. These relatively complex organic molecules are widely used in different industries such as leather tanning, food processing, paper making, cosmetics, textile, and plastics. As a water-soluble member of synthetic dyes, Congo red is used in a huge quantity in textile and biochemistry based industries [28]. It is a benzidine-based anionic dye that was discovered by Paul Bottinger in 1883. Generally, benzidine-based dyes are toxic and highly carcinogenic. Congo red is known to metabolize to benzidine, which is a carcinogen and mutagen compound for humans. Due to the high toxicity and carcinogenicity of Congo red, its use is banned in many countries [29].

Until now, various decontamination techniques including biological, chemical, and physical treatments have been adopted to remove toxic compounds especially synthetic organic dyes from environmental media in both industrial and municipal wastewaters [30]. In this regard, the application of membrane separation, adsorption, chemical oxidation, chemical coagulation, biological degradation, etc. is reported [15]. Among the treatment techniques, 
the adsorption strategy provided a simple, low cost, and relatively fast methodology with high efficiency. This conventional strategy is used in advanced wastewater treatment due to its ease of operation, and flexibility in adsorbent design. This method also produces no harmful by-products and prevents sludge formation during the removal process [15]. Until now, various synthetic and natural adsorbents have been used for the adsorption of organic dyes which is discussed in some useful review reports [31-33]. Notably, developing adsorbents with improved characteristics to be used for the adsorption process is an ongoing trend.

Herein, we present the synthesis and characterization of a novel adsorbent of itaconic acid-modified $\mathrm{Cu}-\mathrm{Ca}-\mathrm{Al}$ layered double hydroxide for adsorption purposes. The $\mathrm{Cu}-\mathrm{Ca}-\mathrm{Al}$ layered double hydroxide was synthesized at first and then modified with itaconic acid through a simple approach. To study the applicability of the prepared materials for adsorption purposes, Congo red as an anionic dye was selected to be removed from the aqueous solution. Kinetic studies were also conducted for the prepared materials. To the best of our knowledge, this is the first report to study the potential application of itaconic acid-modified $\mathrm{Cu}-\mathrm{Ca}-\mathrm{Al}$ layered double hydroxide for adsorption purposes.

\section{Experimental section}

\subsection{Materials and methods}

Aluminum nitrate nonahydrate $\left(\mathrm{Al}\left(\mathrm{NO}_{3}\right)_{3} .9 \mathrm{H}_{2} \mathrm{O}, \geq 98.0 \%\right)$, calcium nitrate tetrahydrate $\left(\mathrm{Ca}\left(\mathrm{NO}_{3}\right)_{2} .4 \mathrm{H}_{2} \mathrm{O}, \geq 99.0 \%\right)$, copper(II) nitrate trihydrate $\left(\mathrm{Cu}\left(\mathrm{NO}_{3}\right)_{2} .3 \mathrm{H}_{2} \mathrm{O}, \geq 99.0 \%\right)$, sodium carbonate $\left(\mathrm{Na}_{2} \mathrm{CO}_{3}\right)$, sodium hydroxide $(\mathrm{NaOH})$, and itaconic acid $\left(\mathrm{C}_{5} \mathrm{H}_{6} \mathrm{O}_{4}\right)$ were purchased from Sigma-Aldrich. Acetic acid (99.5\%) and ortho-phosphoric acid (85\%) were obtained from Merck (Darmstadt, Germany). The stock standard solution of Congo red (2000 mg L ${ }^{-1}$ ) 
was prepared in water. Working standard solutions were prepared daily by diluting the stock solution. Deionized water was prepared by a lab-made water purification system.

\subsection{Apparatus}

A double beam UV-Vis spectrophotometer (UV-1601 Shimadzu, Japan) was applied for the determination of dye concentration in the sample solutions at the wavelength of 499 nm. The XRD data were recorded with the help of a Rigaku-DMax 2500 diffractometer (Japanese science and science company, Tokyo, Japan) with $\mathrm{Cu} K_{\alpha}$ radiation at a wavelength of $1.540 \AA$ and the generator working at $40 \mathrm{kV}$. Diffractograms were recorded between $2 \theta$ of 5-70 ${ }^{\circ}$ The FT-IR spectra were recorded on a Jasco-FT-IR-350 (Tokyo, Japan) spectrometer with a wavenumber range from 400 to $4400 \mathrm{~cm}^{-1}$, using the $\mathrm{KBr}$ pellet technique. Scanning electron microscopy (SEM) was performed on a JSM-6510 Series scanning electron microscope (JEOL, Tokyo, Japan). Nitrogen adsorption/desorption analysis was performed using a Belsorp-mini II (BEL Japan Inc., Osaka, Japan) at the temperature of $77 \mathrm{~K}$. Thermogravimetric analysis was performed on an STA 503 (Bahr GmbH, Hullhorst, Germany) analyzer, at a heating rate of $10{ }^{\circ} \mathrm{C} \mathrm{min}^{-1}$ from room temperature to $800{ }^{\circ} \mathrm{C}$ under an inert atmosphere.

\subsection{Synthesis of $\mathrm{Cu}$-Ca-Al-LDH}

The $\mathrm{Cu}-\mathrm{Ca}-\mathrm{Al}-\mathrm{LDH}$ was prepared according to the following procedure. At first, 976 $\mathrm{mg}$ of $\mathrm{Cu}\left(\mathrm{NO}_{3}\right)_{2} \cdot 3 \mathrm{H}_{2} \mathrm{O}(4 \mathrm{mmol}), 954 \mathrm{mg}$ of $\mathrm{Ca}\left(\mathrm{NO}_{3}\right)_{2} \cdot 4 \mathrm{H}_{2} \mathrm{O}(4 \mathrm{mmol})$, and $1.532 \mathrm{~g}$ of $\mathrm{Al}\left(\mathrm{NO}_{3}\right)_{3} \cdot 9 \mathrm{H}_{2} \mathrm{O}(4 \mathrm{mmol})$ were dissolved into $100 \mathrm{~mL}$ of deionized water. In another container, $100 \mathrm{~mL}$ of an aqueous alkaline solution containing $150 \mathrm{mmol} \mathrm{\textrm {L } ^ { - 1 }}$ of $\mathrm{NaOH}$ and 50 mmol L-1 of $\mathrm{Na}_{2} \mathrm{CO}_{3}$ was prepared. Then, the two prepared solutions were slowly added to a $500 \mathrm{~mL}$ round bottom glass flask. The $\mathrm{pH}$ of the solution was kept between 10 and 11 during 
the addition. After the addition, the mixture was stirred at room temperature for $60 \mathrm{~min}$. Then, the temperature of the solution was enhanced to $60{ }^{\circ} \mathrm{C}$ and maintained for $18 \mathrm{~h}$. Afterward, the slurry was cooled and filtered. The prepared material $(\mathrm{Cu}-\mathrm{Ca}-\mathrm{Al}-\mathrm{LDH})$ was washed several times with deionized water and dried in an oven at $85{ }^{\circ} \mathrm{C}$.

\subsection{Synthesis of LDH-ITA}

For the preparation of LDH-ITA, $976 \mathrm{mg}$ of $\mathrm{Cu}\left(\mathrm{NO}_{3}\right)_{2} \cdot 3 \mathrm{H}_{2} \mathrm{O}(4 \mathrm{mmol}), 954 \mathrm{mg}$ of $\mathrm{Ca}\left(\mathrm{NO}_{3}\right)_{2} \cdot 4 \mathrm{H}_{2} \mathrm{O}(4 \mathrm{mmol})$, and $1.532 \mathrm{~g}$ of $\mathrm{Al}\left(\mathrm{NO}_{3}\right)_{3} \cdot 9 \mathrm{H}_{2} \mathrm{O}(4 \mathrm{mmol})$ were dissolved into 100 $\mathrm{mL}$ of deionized water. Then, $100 \mathrm{~mL}$ of an aqueous alkaline solution containing $150 \mathrm{mmol}$

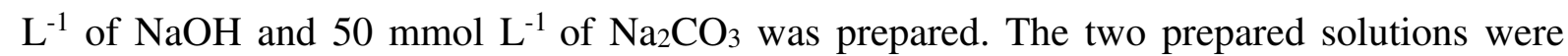
then slowly added to a $500 \mathrm{~mL}$ round bottom flask at room temperature (the $\mathrm{pH}$ of the solution was kept in the range of 10-11). The mixture was stirred for $60 \mathrm{~min}$, heated to 60 ${ }^{\circ} \mathrm{C}$, and then, $50 \mathrm{~mL}$ of water containing $2.5 \mathrm{~g}$ of itaconic acid was poured into the round bottom flask and stirred for $60 \mathrm{~min}$. The mixture was maintained at this step for $18 \mathrm{~h}$ without stirring. The obtained slurry was filtered, washed with deionized water, and dried at $80{ }^{\circ} \mathrm{C}$.

\subsection{Adsorption experiments}

The batch adsorption experiments were conducted to study the adsorption behavior of Congo red onto the prepared adsorbents. For the experiments, $5 \mathrm{~mL}$ of an aqueous solution of Congo red (with the desired concentration) was poured into a $25 \mathrm{~mL}$ Erlenmeyer flask containing the accurately weighed amount of adsorbent. The adsorption was carried out in a water-bath shaker $(298 \mathrm{~K})$ at a shaking speed of $220 \mathrm{rpm}$ for a specific period. After separation of the adsorbent from the solution, the concentration of Congo red in the solution was determined with the help of the UV-Vis spectrophotometer at $499 \mathrm{~nm}$. All the samples 
were filtered through filter papers before analysis. The removal efficiency was calculated using the following equation (Eq. 1):

$$
R E(\%)=\frac{C_{i}-C_{e}}{C_{i}} \times 100
$$

172 In this equation, $C_{i}$ and $C_{e}$ are the initial and equilibrium concentration of Congo red in the 173 solution $\left(\mathrm{mg} \mathrm{L}^{-1}\right)$, respectively. The adsorption capacity $\left(q_{e}, \mathrm{mg} \mathrm{g}^{-1}\right)$ was computed according to the following equation (Eq. 2):

$$
q_{e}=\left(\frac{C_{i}-C_{e}}{W}\right) \times V
$$

176 In this equation, $W$ is the adsorbent amount $(\mathrm{mg})$ and $V$ is the solution volume $(\mathrm{mL})$.

177

\section{Results and discussion}

\subsection{Synthesis and characterization of the materials}

In this study, $\mathrm{Cu}-\mathrm{Ca}-\mathrm{Al}-\mathrm{LDH}$ was prepared in a simple strategy. For the modification of the prepared LDH, itaconic acid was applied. Due to their ability to establish a hydrogen bond between surface hydroxyl groups and functional groups of organic dyes, as well as their ion exchange ability, $\mathrm{Cu}-\mathrm{Ca}-\mathrm{Al}-\mathrm{LDH}$ and LDH-ITA can be used as adsorbents to remove organic dyes from aqueous media. Scheme 1 reveals the structure of these materials and possible interactions during adsorption of Congo red by them form the aqueous solution. 

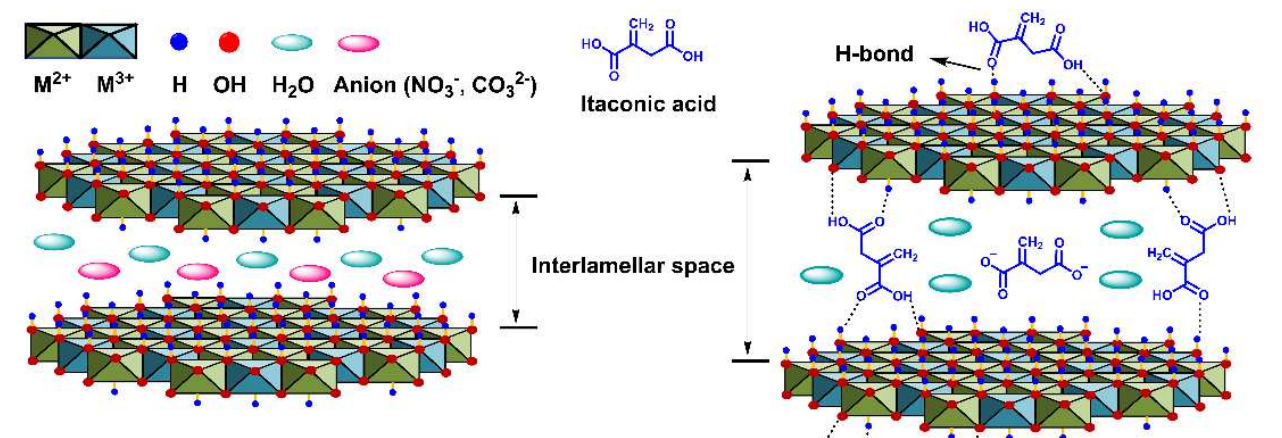

Cu-Ca-AI LDH
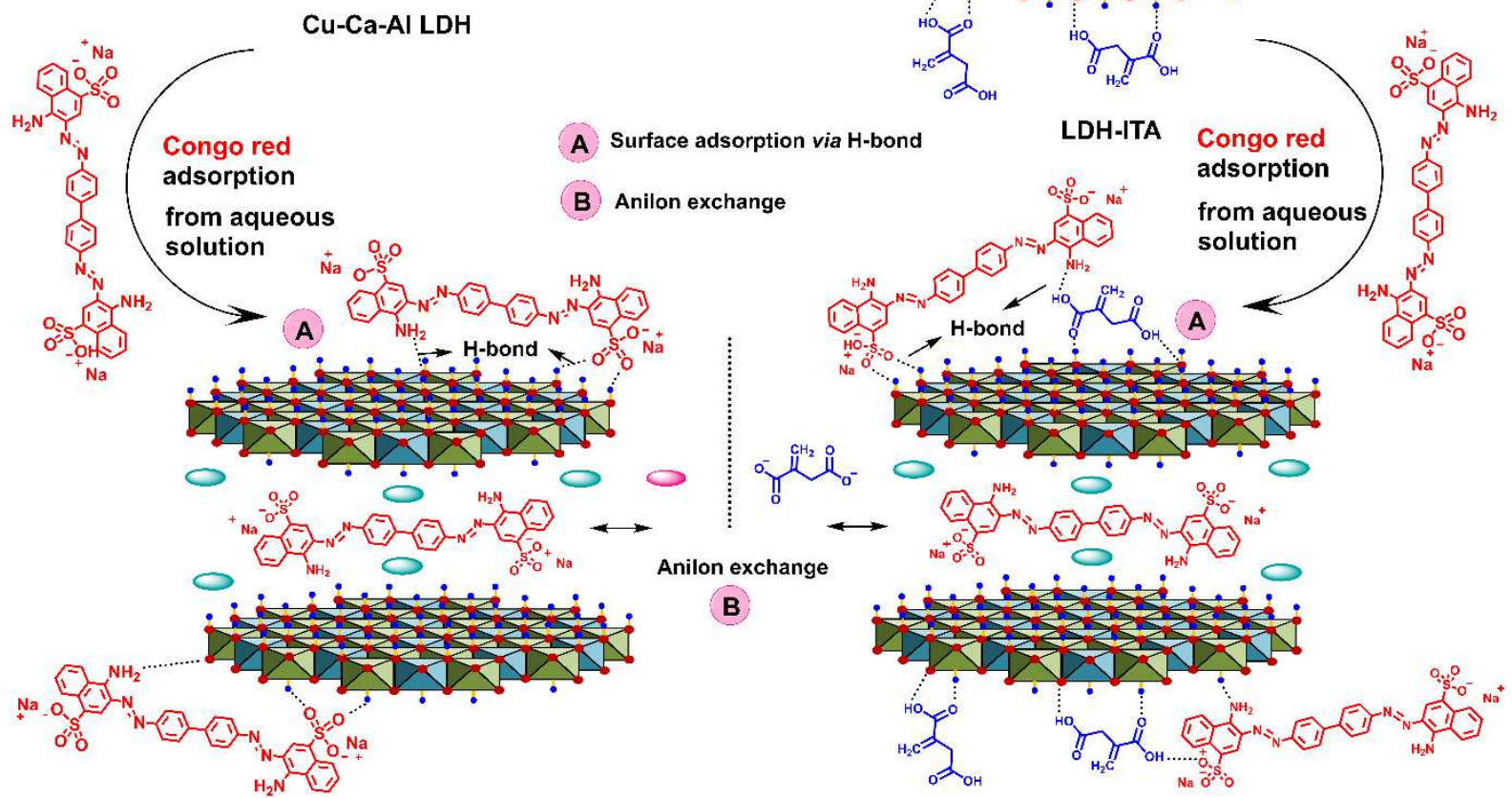

Scheme 1 The schematic representation for structure of Cu-Ca-Al-LDH and LDH-ITA and their application for adsorption of Congo red from the aqueous solutions.

The structure of the prepared materials was further studied using various characterization techniques including FT-IR spectroscopy, X-ray diffraction (XRD), scanning electron microscopy (SEM), $\mathrm{N}_{2}$ adsorption/desorption, and thermogravimetric analysis (TGA).

The FT-IR spectra of the prepared Cu-Ca-Al-LDH and LDH-ITA are shown in Fig. 1. In the case of $\mathrm{Cu}-\mathrm{Ca}-\mathrm{Al}-\mathrm{LDH}$, the broadband located at $3435 \mathrm{~cm}^{-1}$ is associated with the stretching vibration of $\mathrm{O}-\mathrm{H}$ groups in the brucite-like layer and interlayer molecules. The weak band located at around $1633 \mathrm{~cm}^{-1}$ is related to the bending vibration of interlayer water molecules [34]. The band at $1421 \mathrm{~cm}^{-1}$ can be assigned to the characteristic vibration mode of 
$\mathrm{NO}_{3}{ }^{-}$anions in the interlayer of the prepared Cu-Ca-Al-LDH. A series of complicated bands

201

202

203

204

205

206

207

208

209

210

211

212 in the range of $400-1000 \mathrm{~cm}^{-1}$ (such as $876,712,604,515,445 \mathrm{~cm}^{-1}$, etc.) can be attributed to the vibrational modes of the lattice resulting from $\mathrm{M}-\mathrm{O}, \mathrm{O}-\mathrm{M}-\mathrm{O}$, and $\mathrm{M}-\mathrm{O}-\mathrm{M}$ bonds in which the $\mathrm{M}$ represents $\mathrm{Cu}, \mathrm{Ca}$ or $\mathrm{Al}$ [35]. In the case of modified LDH-ITA, the broadband related to the stretching vibration of hydroxyl groups and water molecules in the interlayer space can be seen at $3473 \mathrm{~cm}^{-1}$. The band at $1421 \mathrm{~cm}^{-1}$ disappeared in the case of LDH-ITA, indicating that most of the $\mathrm{NO}_{3}{ }^{-}$ions were replaced by itaconic acid anions. An absorption band at $1384 \mathrm{~cm}^{-1}$ indicated the presence of some carboxylate anions in the modified hydrotalcite structure. The bands located at $1646 \mathrm{~cm}^{-1}$ and $1431 \mathrm{~cm}^{-1}$ are related to the absorption bands of the carboxylic ions (asymmetric and symmetric stretching absorptions). The band at $1565 \mathrm{~cm}^{-1}$ is related to the $\mathrm{C}=\mathrm{C}$ stretching vibration $[36,37]$. These bands indicated the intercalation of itaconic acid.

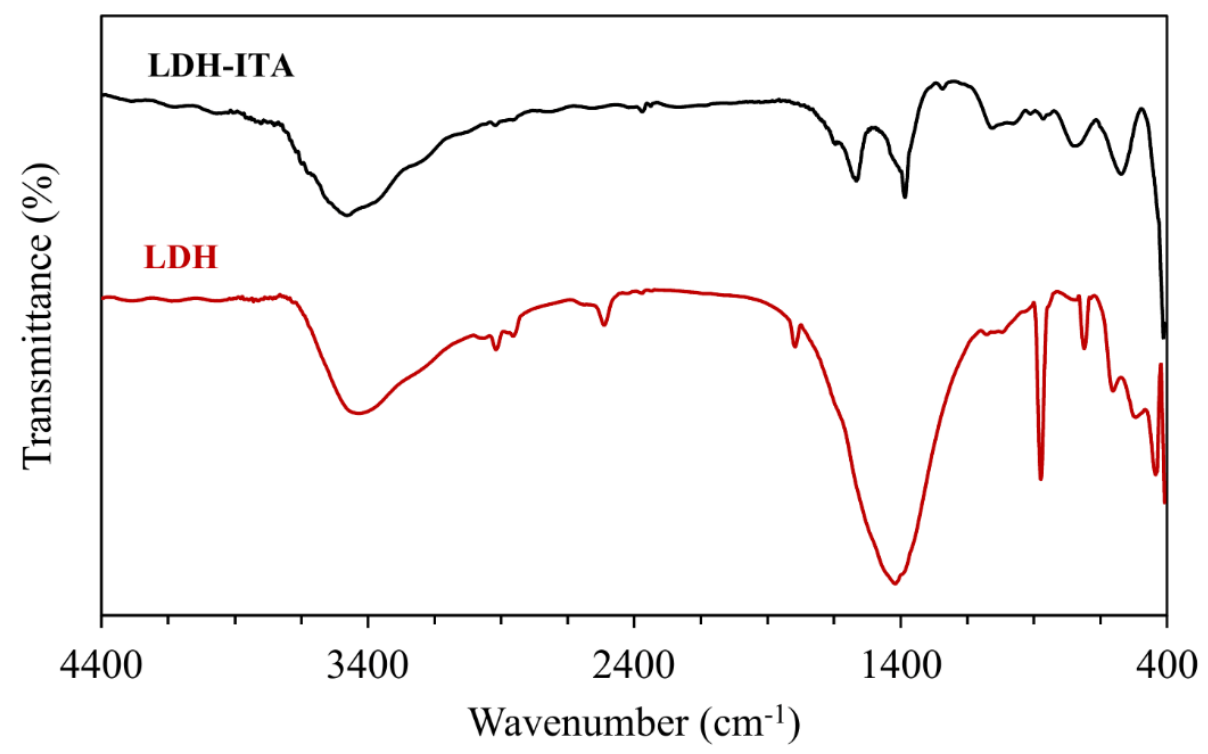

Figure 1. FT-IR spectra of the Cu-Ca-Al-LDH and LDH-ITA.

The XRD patterns of the prepared Cu-Ca-Al-LDH and LDH-ITA are shown in Fig. 2a. In the case of $\mathrm{Cu}-\mathrm{Ca}-\mathrm{Al}-\mathrm{LDH}$, it exhibited characteristic peaks located at $2 \theta=23.1^{\circ}, 29.5^{\circ}$, $35.6^{\circ}, 38.6^{\circ}, 39.5^{\circ}, 43.1^{\circ}, 47.5^{\circ}, 48.5^{\circ}$, etc. which is in accordance with previous reports [38]. In this regard, the peaks at $35.6^{\circ}$ and $38.6^{\circ}$ correspond to $\mathrm{CuO}$. The presence of 
characteristic peaks related to $\mathrm{CaCO}_{3}\left(23.4^{\circ}, 29.5^{\circ}, 36.9^{\circ}, 39.5^{\circ}, 43.1^{\circ}, 47.5^{\circ}\right.$, and $\left.48.5^{\circ}\right)$ is detected in the XRD pattern, which is in agreement with the previous reports on the synthesis of $\mathrm{Ca}-\mathrm{Al} \mathrm{LDHs}[39,40]$. In the LDH-ITA, some diffraction peaks disappeared or weakened.

221 In contrast, some diffraction peaks became stronger or new peaks appeared. These 222 observations combined with the earlier FTIR analyses indicated that itaconic acid was incorporated into the $\mathrm{Cu}-\mathrm{Ca}-\mathrm{Al}-\mathrm{LDH}$ structure.

224

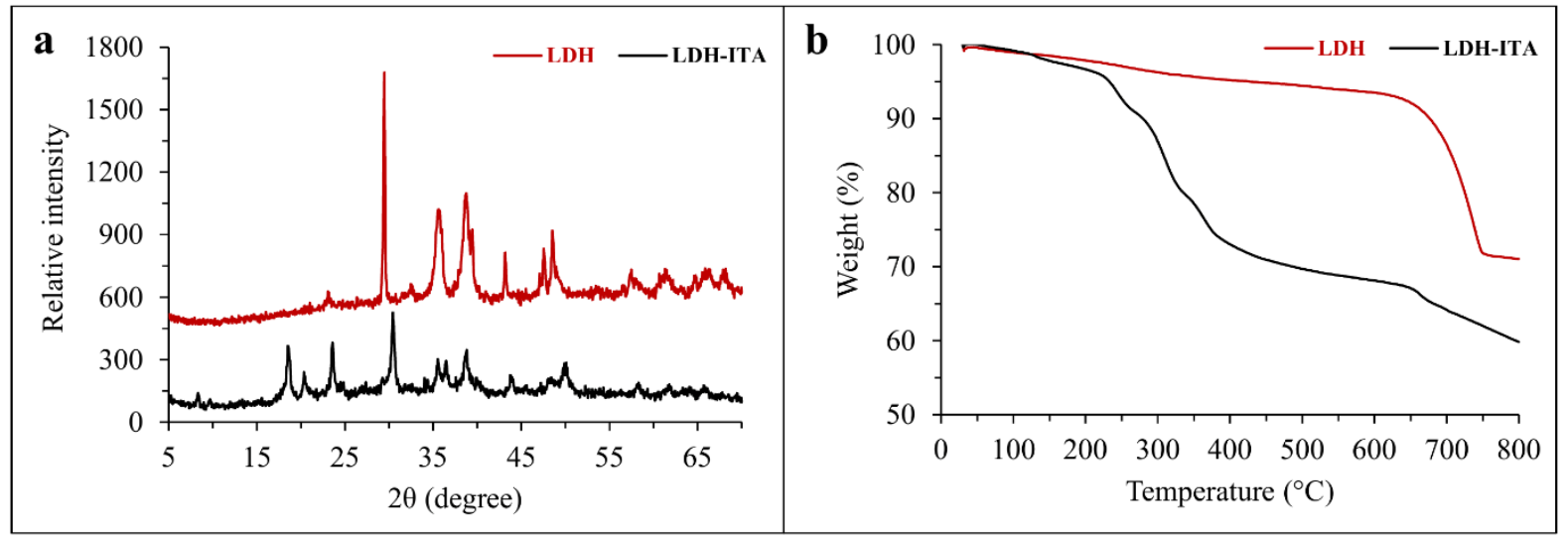

Figure 2. The XRD patterns (a) and the TGA thermograms (b) of the prepared $\mathrm{Cu}-\mathrm{Ca}-\mathrm{Al}-$ LDH and LDH-ITA.

The TGA curves of the prepared Cu-Ca-Al-LDH and LDH-ITA are shown in Fig. $2 b$. In the case of $\mathrm{Cu}-\mathrm{Ca}-\mathrm{Al}-\mathrm{LDH}$, a mass loss between 30 to $235^{\circ} \mathrm{C}$ (about $2.7 \%$ ) is mainly due to the removal of physically-adsorbed and interlayered water [36]. Another mass loss occurred between 235 to $580{ }^{\circ} \mathrm{C}$ (about 3.7\%) which may be attributed to the decomposition of the lamina $-\mathrm{OH}$ groups. In this stage, the layered structure of the $\mathrm{Cu}-\mathrm{Ca}-\mathrm{Al}-\mathrm{LDH}$ was gradually degraded. A final mass loss occurred in the range of 580 to $800{ }^{\circ} \mathrm{C}$ (about $22.6 \%$ ). This mass loss is related to the dehydroxylation of the $\mathrm{Cu}-\mathrm{Ca}-\mathrm{Al}-\mathrm{LDH}$ laminates and the formation of copper, calcium, and aluminum oxides. The $\mathrm{Cu}-\mathrm{Ca}-\mathrm{Al}-\mathrm{LDH}$ exhibited a total mass loss of $29.0 \%$. In the case of LDH-ITA, when the temperature was increased to near $200{ }^{\circ} \mathrm{C}$, decomposition of itaconic acid began. The mass loss of LDH-ITA is considerably 
higher than that of the unmodified $\mathrm{Cu}-\mathrm{Ca}-\mathrm{Al}-\mathrm{LDH}$. The LDH-ITA showed a total mass loss of $40.0 \%$ from 30 to $800{ }^{\circ} \mathrm{C}$.

The FESEM images of the prepared Cu-Ca-Al-LDH and LDH-ITA are shown in Fig. 3 at three magnifications. The plate-like morphology of both $\mathrm{Cu}-\mathrm{Ca}-\mathrm{Al}-\mathrm{LDH}$ and LDH-ITA crystallites is observable in the images. They exhibited a lamellar structure with sharp edges [38]. Also, the prepared $\mathrm{Cu}-\mathrm{Ca}-\mathrm{Al}-\mathrm{LDH}$ shows more aggregation in comparison with modified LDH (LDH-ITA). This may be due to the formation of hydrogen bonds on the surface of the Cu-Ca-Al-LDH. In the case of LDH-ITA, the degree of reunion is reduced, and the particle size decreased [36].

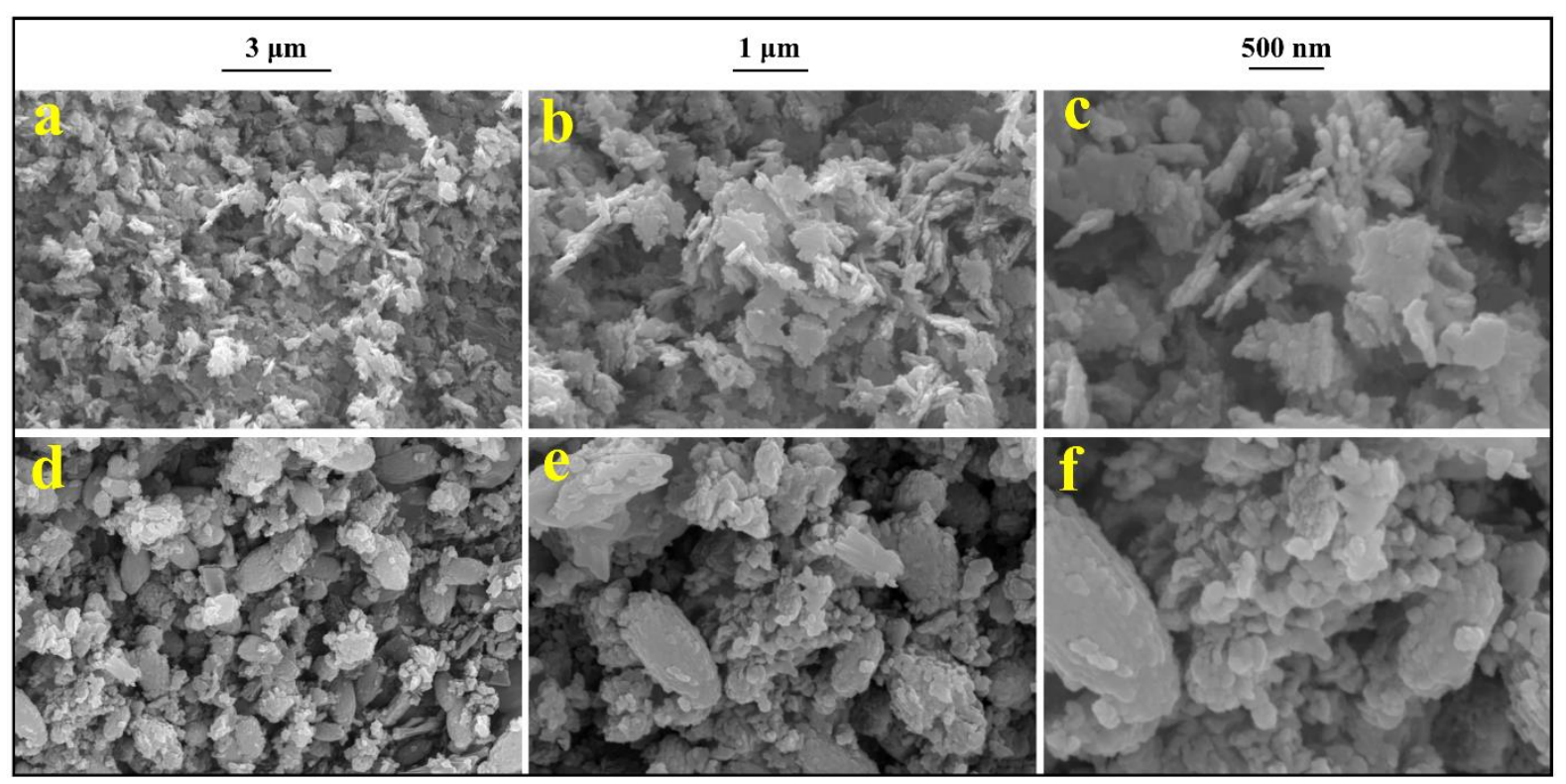

Figure 3. The scanning electron micrographs of the prepared $\mathrm{Cu}-\mathrm{Ca}-\mathrm{Al}-\mathrm{LDH}(\mathrm{a}-\mathrm{c})$ and LDHITA (d-f) with different magnifications.

The $\mathrm{N}_{2}$ adsorption/desorption isotherms of the prepared $\mathrm{Cu}-\mathrm{Ca}-\mathrm{Al}-\mathrm{LDH}$ and LDH-ITA are shown in Fig. 4. As can be seen in Fig. 4, Cu-Ca-Al-LDH showed a combination of type III and IV isotherms with H3-type hysteresis loops according to the IUPAC classification. The LDH-ITA exhibited IV type isotherm with H3-type hysteresis loops. The calculated parameters are shown in Table 1. The prepared Cu-Ca-Al-LDH showed a BET surface area of $15.6 \mathrm{~m}^{2} \mathrm{~g}^{-1}$ while LDH-ITA exhibited a BET surface area of $24.8 \mathrm{~m}^{2} \mathrm{~g}^{-1}$. Also, pore 

respectively.

257

261

262

263

264

265

266

267

268

269
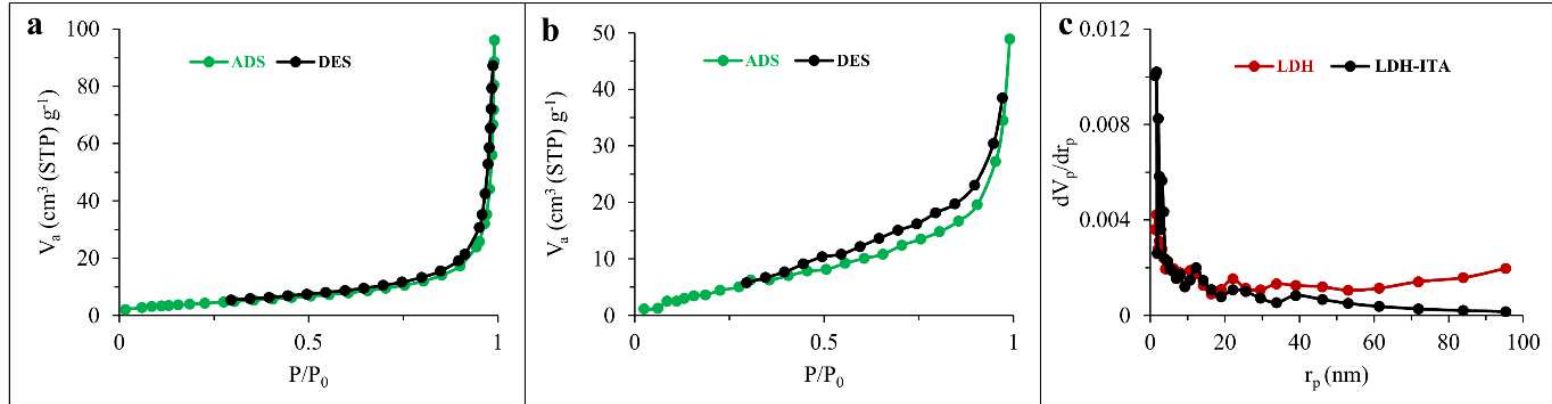

Figure 4. The N2 adsorption/desorption isotherms of Cu-Ca-Al-LDH (a), LDH-ITA (b), and the BJH pore size distribution curves of the samples (c).

Table 1. Textural properties of the synthesized materials.

\begin{tabular}{lccc}
\hline \multirow{2}{*}{ Sample } & \multicolumn{2}{c}{ BET } & \multicolumn{2}{c}{ BJH } \\
\cline { 2 - 4 } & $\begin{array}{c}\text { Surface area } \\
\left(\mathrm{m}^{2} \mathrm{~g}^{-1}\right)\end{array}$ & $\begin{array}{c}\mathrm{V}_{\mathrm{p}} \\
\left(\mathrm{cm}^{3} \mathrm{~g}^{-1}\right)\end{array}$ & $\begin{array}{c}\mathrm{r}_{\mathrm{p}} \\
(\mathrm{nm})\end{array}$ \\
\hline LDH & 15.6 & 0.142 & 1.64 \\
LDH-ITA & 24.8 & 0.080 & 1.64 \\
\hline
\end{tabular}

\subsection{Adsorption studies}

\subsubsection{The effect of $p H$ on adsorption}

To study the effect of sample solution $\mathrm{pH}$ on the adsorption of Congo red onto the $\mathrm{Cu}$ Ca-Al-LDH and LDH-ITA adsorbents, sample solution pHs between 5.0 and 9.0 were investigated. This range was selected due to the instability of Congo red below pH 5 [28]. All the experiments were done using $5 \mathrm{~mL}$ of an aqueous sample solution containing $50 \mathrm{mg} \mathrm{L}^{-1}$ of Congo red with the adsorbent dosage of $10.0 \mathrm{mg}$. The adsorption was performed at $298 \mathrm{~K}$ for $3 \mathrm{~h}$ with the help of magnetic stirring at $1500 \mathrm{rpm}$. After the adsorption procedure, the adsorbent was separated from the sample solution utilizing centrifugation (6000 rpm, $10 \mathrm{~min}$ ) and the concentration of remained dye in the sample solution was determined using UV-Vis spectroscopy. The data are shown in Fig. 5a. As can be seen in Fig. 5a, with increasing 
solution $\mathrm{pH}$ from 5.0 to 9.0, a continuous decrease in the removal efficiency of the two

274 adsorbents was observed. The decrease in the Congo red removal efficiency is may be due to that the surface of the adsorbents becomes highly negative when $\mathrm{pH}$ increased from 5.0 to 9.0. The negative charge on the surface of the adsorbents results in electrostatically repelling of negatively charged Congo red [28]. Accordingly, $\mathrm{pH}=5.0$ was selected for further experiments.
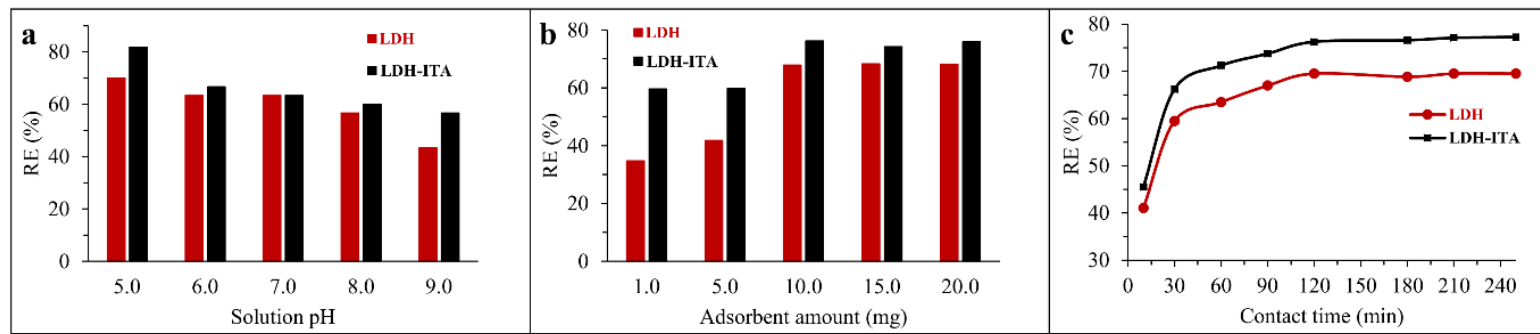

Figure 5. The effect of $\mathrm{pH}$ (a), adsorbent amount (b), and contact time (c) on the adsorption of Congo red by the prepared adsorbents.

\subsubsection{The effect of the adsorbent amount}

The effect of adsorbent amount on the adsorption of Congo red onto the $\mathrm{Cu}-\mathrm{Ca}-\mathrm{Al}$ LDH, and LDH-ITA was studied in the range of 1.0-20.0 mg. In these experiments, $5 \mathrm{~mL}$ of a standard aqueous solution of Congo red at the concentration level of $50 \mathrm{mg} \mathrm{L}^{-1}(\mathrm{pH}=5.0)$ was used. The experiments were performed at $298 \mathrm{~K}$ for $3 \mathrm{~h}$ with the help of magnetic stirring at $1500 \mathrm{rpm}$. After separation of the adsorbent from the sample solution (centrifugation at 6000 rpm for $10 \mathrm{~min}$ ), the concentration of remained dye in the sample solution was determined using UV-Vis spectroscopy. As can be seen in Fig. 5b, the removal efficiency for two adsorbents was enhanced by enhancing the adsorbent amount from 1.0 to $10.0 \mathrm{mg}$ and no further enhancement in removal efficiency was observed for higher adsorbent amounts. Based on the results, $10.0 \mathrm{mg}$ of each of the adsorbents were selected as the adsorbent amount for further experiments. 


\subsubsection{The effect of contact time}

297

To study the effect of contact time on the adsorption of Congo red onto the $\mathrm{Cu}-\mathrm{Ca}-\mathrm{Al}-$

LDH and LDH-ITA adsorbents, various contact times between 10-250 min were investigated.

In the experiments, $5 \mathrm{~mL}$ of a standard solution of Congo red at the concentration level of 50 mg $\mathrm{L}^{-1}(\mathrm{pH}=5.0)$ with an adsorbent dosage of $10.0 \mathrm{mg}$ was used. The adsorption was performed at $298 \mathrm{~K}$. After separation of the adsorbent from the sample solution (centrifugation at $6000 \mathrm{rpm}$ for $10 \mathrm{~min}$ ), the concentration of the remained dye in the sample solution was determined. Figure $5 \mathrm{c}$ shows the effect of contact time on Congo red removal by the prepared adsorbents. A remarkable enhancement in removal efficiency was observed for the two adsorbents when contact time was increased from 10 to $120 \mathrm{~min}$. Longer times had no significant effect on the adsorption efficiency. The obtained data revealed a relatively fast adsorption process. The high accessible sites of the adsorbents are mainly responsible for this fast adsorption. Based on the results, a contact time of 120 min was used for further experiments to ensure that equilibrium is reached. conducted. The kinetic models of pseudo-first-order (PFO), pseudo-second-order (PSO), Elovich, and intra-particle diffusion (IPD) were studied. The used equations are expressed in the following equations:

\subsubsection{The adsorption kinetic studies}

To better understanding and study the mechanism of adsorption, kinetic studies were

$$
\log \left(q_{e}-q_{t}\right)=\log q_{e}-\frac{k_{1}}{2.303} t
$$

$$
\frac{t}{q_{t}}=\frac{1}{h}+\frac{1}{q_{e}} t
$$

$$
h=k_{2} \times q_{e}^{2}
$$




$$
q_{t}=\frac{\ln (\alpha \beta)}{\beta}+\frac{\ln t}{\beta}
$$

$$
q_{t}=k_{d i f}(t)^{0.5}+C
$$

In these equations, $q_{e}\left(\mathrm{mg} \mathrm{g}^{-1}\right), q_{t}\left(\mathrm{mg} \mathrm{g}^{-1}\right), k_{1}\left(\mathrm{~min}^{-1}\right), h\left(\mathrm{mg} \mathrm{g}^{-1} \min ^{-1}\right), k_{2}\left(\mathrm{~g} \mathrm{mg}^{-1} \min ^{-}\right.$ $\left.{ }^{1}\right), \alpha\left(\mathrm{mg} \mathrm{g}^{-1} \min ^{-1}\right) \& \beta\left(\mathrm{g} \mathrm{mg}^{-1}\right), k_{\text {dif }}\left(\mathrm{mg} \mathrm{g}^{-1} \min ^{-0.5}\right)$, and $C\left(\mathrm{mg} \mathrm{g}^{-1}\right)$ are the adsorption capacity at equilibrium, the adsorption capacity at time t, PFO rate constant, the initial sorption rate in PSO model, PSO rate constant, Elovich constants, IPD rate constant, and a constant, respectively. The results of the fitting are shown in Fig. 6 and Table 2. Data showed that, for both adsorbents, the PSO kinetic model provided better $\mathrm{R}^{2}$ values than those obtained by other models. Accordingly, the physiochemical adsorption process can be well described with the PSO model.

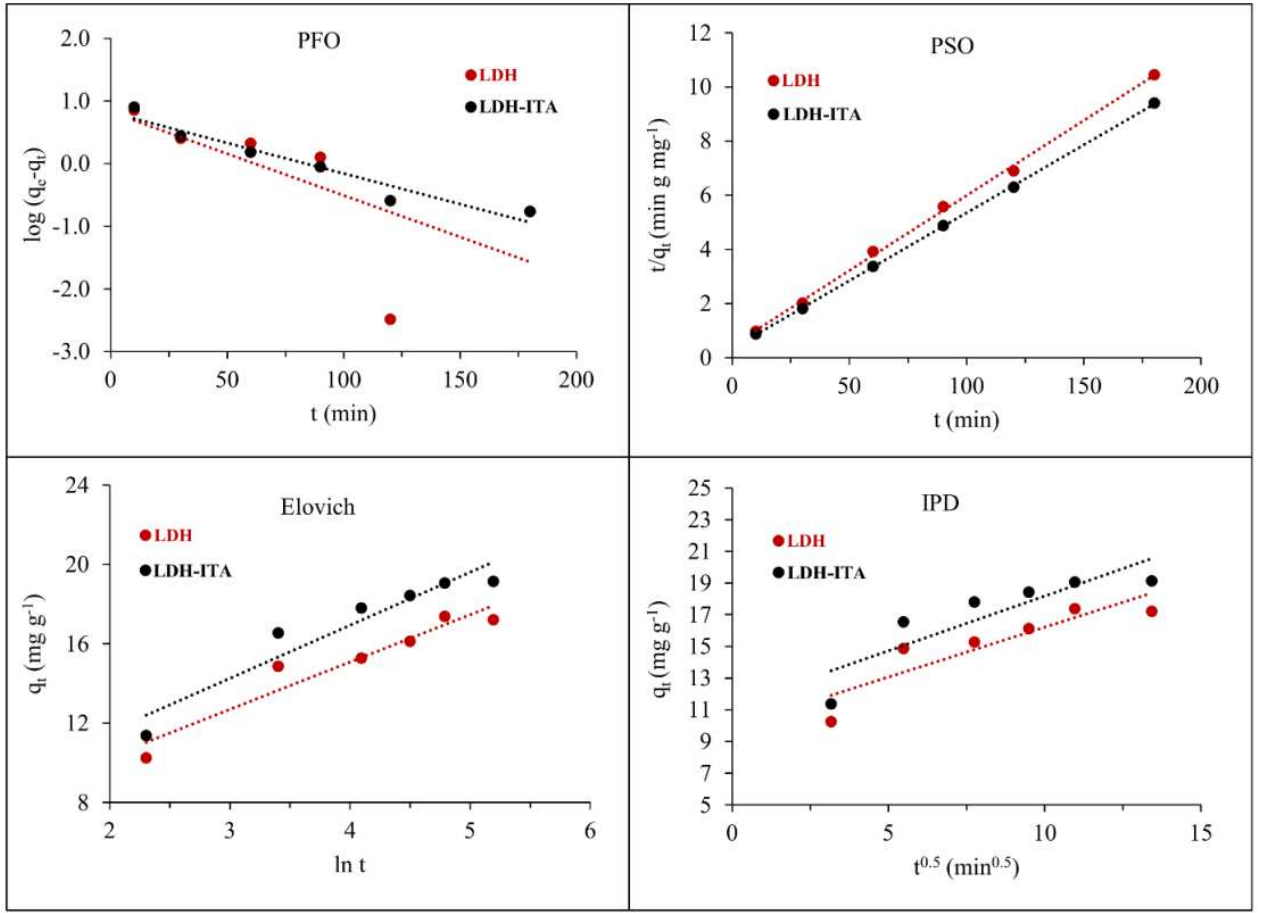

Figure 6. The kinetic adsorption models of pseudo-first-order (PFO), pseudo-second-order (PSO), Elovich, and intra-particle diffusion (IPD) for adsorption of Congo red by the prepared adsorbents. 
Table 2. Parameters obtained by kinetic models for the adsorption of Congo red onto LDH and LDH-ITA.

\begin{tabular}{llllll}
\hline Model & Adsorbent & $\mathrm{R}^{2}$ & Parameters $^{\mathrm{a}}$ & & \\
\hline PFO & LDH & 0.4668 & $k_{1}=0.0306$ & $q_{e}=6.6$ & \\
& LDH-ITA & 0.9347 & $k_{1}=0.0223$ & $q_{e}=6.5$ & \\
PSO & LDH & 0.9985 & $k_{2}=0.0068$ & $q_{e}=18.0$ & $h=2.227$ \\
& LDH-ITA & 0.9998 & $k_{2}=0.0073$ & $q_{e}=20.0$ & $h=2.890$ \\
Elovich & LDH & 0.9186 & $\alpha=24.26$ & $\beta=0.4190$ & \\
& LDH-ITA & 0.9106 & $\alpha=27.64$ & $\beta=0.3740$ & \\
& & & & & \\
IPD & LDH & 0.7977 & $k_{d i f}=0.6283$ & $C=9.93$ & \\
& LDH-ITA & 0.7623 & $k_{d i f}=0.6911$ & $C=11.28$ & \\
\hline
\end{tabular}

${ }^{\mathrm{a}}$ The units are as same as mentioned in section 3.2.4.

\subsubsection{The effect of Congo red concentration and adsorption isotherm}

To study the effect of Congo red initial concentration, concentrations between 10 and $300 \mathrm{mg} \mathrm{L}^{-1}(\mathrm{pH}=5.0)$ were studied. An adsorbent dosage of $10.0 \mathrm{mg}$ was applied and the adsorption time was set to $120 \mathrm{~min}$. The obtained data are shown in Fig. 7a. Maximum adsorption capacities of 81 and $84 \mathrm{mg} \mathrm{g}^{-1}$ were obtained using Cu-Ca-Al-LDH and LDH-ITA adsorbents, respectively. To study the equilibrium adsorption, Langmuir, Freundlich, and Dubinin-Radushkevich (D-R) isotherm models were investigated. The equations of the linear forms of the applied isotherm models are as follows:

$$
\frac{C_{e}}{q_{e}}=\frac{1}{q_{\max } \times k_{L}}+\frac{C_{e}}{q_{\max }}
$$

$$
\log q_{e}=\frac{1}{n} \log C_{e}+\log k_{F}
$$

$$
\ln q_{e}=\ln q_{\max }-B\left(R T \ln \left(1+\frac{1}{C_{e}}\right)\right)^{2}
$$

In these equations, $C_{e}\left(\mathrm{mg} \mathrm{L}^{-1}\right), q_{e}\left(\mathrm{mg} \mathrm{g}^{-1}\right), q_{\max }\left(\mathrm{mg} \mathrm{g}^{-1}\right), k_{L}\left(\mathrm{~L} \mathrm{mg}^{-1}\right), n \& k_{F}\left(\left(\mathrm{mg} \mathrm{g}^{-1}\right)\right.$ $\left.\left(\mathrm{L} \mathrm{mg}^{-1}\right)^{1 / \mathrm{n}}\right), B\left(\mathrm{~mol}^{2} \mathrm{~kJ}^{-2}\right), R\left(\mathrm{j} \mathrm{mol}^{-1} \mathrm{~K}^{-1}\right)$, and $T(\mathrm{~K})$ are the concentration of Congo red at 
equilibrium, adsorption capacity at equilibrium, the maximum adsorption capacity of

353

354

355

356

357

358

359

360

361

362

366

367

368

369

adsorbent, the Langmuir constant, the Freundlich isotherm constants for adsorption capacity and adsorption intensity, the Dubinin-Radushkevich isotherm constant, the universal gas constant, and temperature, respectively. Figure 7 and Table 3 show the adsorption isotherms and the calculated parameters. Considering the $\mathrm{R}^{2}$ value, the Freundlich model showed the best fit with the experimental data obtained by both adsorbents. The $\mathrm{R}^{2}$ values of the Freundlich model were obtained 0.9411 and 0.9320 for $\mathrm{Cu}-\mathrm{Ca}-\mathrm{Al}-\mathrm{LDH}$ and LDH-ITA adsorbents, respectively. The Freundlich adsorption isotherm model representing multilayer, heterogeneous adsorption sites.
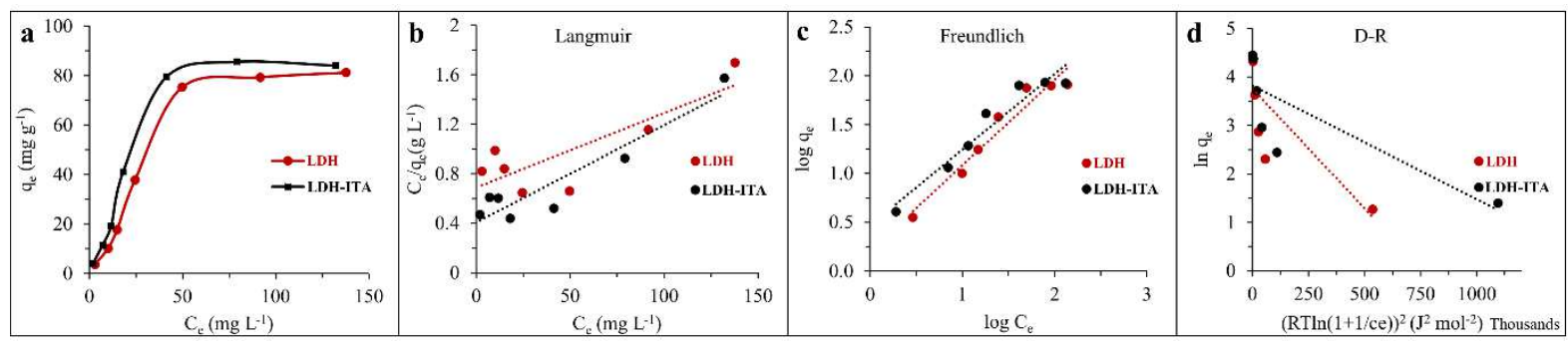

Figure 7. The equilibrium isotherm (a) and the isotherm models of Langmuir (b), Freundlich (c), and Dubinin-Radushkevich (d) for adsorption of Congo red by the prepared adsorbents.

Table 3 The parameters obtained by isotherm models for the adsorption of Congo red onto LDH and LDH-ITA.

\begin{tabular}{lllll}
\hline Model & Adsorbent & $\mathrm{R}^{2}$ & Parameters $^{\mathrm{a}}$ & \\
\hline Langmuir & LDH & 0.6805 & $k_{L}=0.0087$ & $q_{\max }=166.6$ \\
& LDH-ITA & 0.8782 & $k_{L}=0.0194$ & $q_{\max }=126.6$ \\
Freundlich & LDH & 0.9411 & $k_{F}=1.620$ & $n=1.142$ \\
& LDH-ITA & 0.9320 & $k_{F}=2.945$ & $n=1.289$ \\
D-R & LDH & 0.6479 & $B=4.93 \times 10^{-6}$ & $q_{\max }=42.5$ \\
& LDH-ITA & 0.6450 & $B=2.34 \times 10^{-6}$ & $q_{\max }=45.6$ \\
\hline
\end{tabular}

${ }^{\text {a }}$ The units are as same as mentioned in section 3.2.5.

\subsection{Comparison study}

Contact time (equilibrium time) and adsorption capacity are two important factors in the adsorption process of an adsorbate species by an adsorbent material. The shorter and higher 
the adsorption time and the adsorbent capacity, respectively, the more efficient the adsorption process. Table 4 compares the adsorption capacities of several adsorbents as well as corresponding optimal adsorption conditions. As shown in Table 4, the highest adsorption capacities were observed at acidic pHs for all adsorbents. Also, compared to the adsorbents reported in Table 4, adsorbents synthesized in this work have a shorter adsorption time and a higher adsorption capacity, which indicates the acceptable performance of these adsorbents. One possible reason for observing this acceptable performance is the adsorption mechanism, which occurs in both anion exchange and surface adsorption by H-bonding pathway as depicted in Scheme 1.

Table 4. Comparison of a maximum adsorption capacities of $\mathrm{Cu}-\mathrm{Ca}-\mathrm{Al}-\mathrm{LDH}$ and LDH-ITA for removal of Congo red dye by various reported adsorbents.

\begin{tabular}{lllll}
\hline Adsorbents $^{a}$ & $q_{m a}\left(\mathrm{mg} \mathrm{g}^{-1}\right)$ & $\mathrm{pH}$ & Equilibrium time (min) & Ref. \\
\hline $\mathrm{Cu}^{-C a-A l-L D H}$ & 81 & 5.0 & 120 & This work \\
LDH-ITA & 84 & 5.0 & 120 & This work \\
AuNPs-coated AC & 71 & 6.5 & 270 & {$[41]$} \\
AgNPs-coated AC & 64 & 6.5 & 270 & {$[41]$} \\
$p$ TSA-Pani @ GO-CNT & 66 & 5.0 & 300 & {$[42]$} \\
Neem leaf powder & 41 & 6.7 & 300 & {$[43]$} \\
hollow ZnFe $\mathrm{O}_{4}$ microspheres & 16 & 6.0 & 120 & {$[44]$} \\
Aspergillus niger biomass & 14 & 6.0 & 1800 & {$[45]$} \\
\hline${ }^{a}$ NPs: nanoparticles; AC: activated carbon; pTSA: para toluene sulfonic & acid; Pani: \\
polyaniline; GO: graphene oxide; CNT: multiwalled carbon nanotube. & \\
\hline
\end{tabular}

\section{Conclusions}

In conclusion, $\mathrm{Cu}-\mathrm{Ca}-\mathrm{Al} / \mathrm{NO}_{3}-\mathrm{LDH}$ was functionalized with itaconic acid. Water as an environmentally-friendly solvent was used in the synthesis procedures. The prepared materials were applied as novel adsorbents for adsorption purposes. The newly prepared materials showed good performance toward Congo red removal from aqueous solutions. The effect of experimental parameters (sample solution $\mathrm{pH}$, adsorbent dosage, contact time, and initial concentration of the dye) was studied. The kinetic studies showed that the best fit was 

achieved with the pseudo-second-order model for the adsorption of Congo red using the two 391 prepared adsorbents. Three isotherm models were used to investigate the equilibrium 392 adsorption studies. The data showed that the Freundlich model showed the best fit with $\mathrm{R}^{2}$ 393 values of 0.9411 and 0.9320 for $\mathrm{Cu}-\mathrm{Ca}-\mathrm{Al}-\mathrm{LDH}$ and LDH-ITA adsorbents, respectively. 394 Maximum adsorption capacities of 81 and $84 \mathrm{mg} \mathrm{g}^{-1}$ were obtained using $\mathrm{Cu}-\mathrm{Ca}-\mathrm{Al}-\mathrm{LDH}$ and 395 LDH-ITA adsorbents, respectively. Finally, the prepared adsorbents showed acceptable 396 characteristics to be considered as effective adsorbents for anionic dye (e.g. Congo red) 397 removal from aqueous media.

398

\section{Conflict of interest}

400 The authors declare no competing financial interest.

401

\section{Acknowledgment}

403 The authors wish to thank the research council of the Isfahan University of Technology.

404

405 


\section{References}

407 [1] Z. Babaei, A.N. Chermahini, M. Dinari, M. Saraji, A. Shahvar, A sulfonated triazine-based covalent organic polymer supported on a mesoporous material: a new and robust material for the production of 5-hydroxymethylfurfural, Sustainable Energy \& Fuels, 3, 1024-1032 (2019).

[2] A. Shahzeydi, M. Ghiaci, H. Farrokhpour, A. Shahvar, M. Sun, M. Saraji, Facile and green synthesis of copper nanoparticles loaded on the amorphous carbon nitride for the oxidation of cyclohexane, Chemical Engineering Journal, 370, 1310-1321 (2019).

[3] M. Rezaie, M. Dinari, A.N. Chermahini, M. Saraji, A. Shahvar, Preparation of kapa carrageenanbased acidic heterogeneous catalyst for conversion of sugars to high-value added materials, International Journal of Biological Macromolecules, 165, 1129-1138 (2020).

[4] Q. Zhang, E. Uchaker, S.L. Candelaria, G. Cao, Nanomaterials for energy conversion and storage, Chemical Society Reviews, 42, 3127-3171 (2013).

[5] K. Pyrzynska, Use of nanomaterials in sample preparation, TrAC Trends in Analytical Chemistry, 43, 100-108 (2013).

[6] M. Ahmadi, H. Elmongy, T. Madrakian, M. Abdel-Rehim, Nanomaterials as sorbents for sample preparation in bioanalysis: A review, Analytica Chimica Acta, 958, 1-21 (2017).

[7] A. Shahvar, R. Soltani, M. Saraji, M. Dinari, S. Alijani, Covalent triazine-based framework for micro solid-phase extraction of parabens, Journal of Chromatography A, 1565, 48-56 (2018).

[8] M. Saraji, A. Shahvar, Metal-organic aerogel as a coating for solid-phase microextraction, Analytica Chimica Acta, 973, 51-58 (2017).

[9] S. Zhao, X. Fan, J. Yang, H. Huang, C. Xia, R. Jing, M. Wu, Z. Zhang, A. Liu, Q. Zhang, Z.

Enhanced removal of $\mathrm{Cr}(\mathrm{VI})$ from wastewater by nanoscale zero valent iron supported on layered

428 double hydroxides, Journal of Porous Materials 27, 1701-1710 (2020).

429 [10] M. Dinari, N. Roghani, Calcium Iron Layered Double Hydroxide/Poly(vinyl chloride) 430 Nanocomposites: Synthesis, Characterization and Cd2+ Removal Behavior, Journal of Inorganic and 431 Organometallic Polymers and Materials, 30, 808-819 (2020). 
433 adsorption of amoxicillin from aqueous solutions by L-methionine modified montmorillonite K10,

434 Colloids and Surfaces A:, 611, 125792 (2021).

435 [12] E. S. Behbahani, K. Dashtian, M. Ghaedi, Fe/Co-chalcogenide-stabilized Fe3O4 nanoparticles supported MgAl-layered double hydroxide as a new magnetically separable sorbent for the simultaneous spectrophotometric determination of anionic dyes, Microchemical Journal, 152, 104431 (2020).

[13] M. Dinari, S. Neamati, Surface modified layered double hydroxide/polyaniline nanocomposites: Synthesis, characterization and $\mathrm{Pb}^{2+}$ removal, Colloids and Surfaces A:, 598, 124438 (2020).

[14] M. Dinari, R. Soltani, G. Mohammadnezhad, Kinetics and thermodynamic study on novel modified-mesoporous silica MCM-41/polymer matrix nanocomposites: effective adsorbents for trace CrVI removal, Journal of Chemical \& Engineering Data, 62, 2316-2329 (2017).

[15] R. Soltani, A. Shahvar, H. Gordan, M. Dinari, M. Saraji, Covalent triazine framework-decorated phenyl-functionalised SBA-15: its synthesis and application as a novel nanoporous adsorbent, New Journal of Chemistry, 43, 13058-13067 (2019).

[16] K.-H. Goh, T.-T. Lim, Z. Dong, Application of layered double hydroxides for removal of oxyanions: a review, Water research, 42, 1343-1368 (2008).

[17] A. Mokhtar, S. Abdelkrim, F. Zaoui, M. Sassi, B. Boukoussa, Improved Stability of Starch@Layered-Materials Composite Films for Methylene Blue Dye Adsorption in Aqueous Solution, Journal of Inorganic and Organometallic Polymers and Materials, 29, 1807-1817 (2019). in: Layered double hydroxides, Springer, pp. 89-119 (2006).

[19] X. Duan, D.G. Evans, Layered double hydroxides, Springer Science \& Business Media, 2006.

[20] H. Nabipour, Controlled release of Diclofenac, an anti-inflammatory drug by nanocompositing with layered zinc hydroxide, Journal of Inorganic and Organometallic Polymers and Materials, 30, 3826-3831 (2020). advances and perspectives, Chemical Society Reviews, 43, 7040-7066 (2014). 

tailored for energy conversion and storage, Materials today, 19, 213-226 (2016).

[23] H. Pang, Y. Wu, X. Wang, B. Hu, X. Wang, Recent advances in composites of graphene and layered double hydroxides for water remediation: a review, Chemistry-An Asian Journal, 14, 25422552 (2019).

[24] M. Zubair, M. Daud, G. McKay, F. Shehzad, M.A. Al-Harthi, Recent progress in layered double hydroxides (LDH)-containing hybrids as adsorbents for water remediation, Applied Clay Science, $143,279-292(2017)$.

[25] H. Wang, X. Li, J. Ma, Q. Jia, Facile synthesis of polymer monolith functionalized with layered double hydroxide as effective preconcentration materials for fluorescent whitening agents, Microchemical Journal, 132, 1071-1077 (2017).

[26] R. Soltani, A. Shahvar, M. Dinari, M. Saraji, Environmentally-friendly and ultrasonic-assisted preparation of two-dimensional ultrathin $\mathrm{Ni} / \mathrm{Co}-\mathrm{NO}_{3}$ layered double hydroxide nanosheet for micro solid-phase extraction of phenolic acids from fruit juices, Ultrasonics Sonochemistry, 40, 395-401 (2018).

[27] M. Laipan, J. Yu, R. Zhu, J. Zhu, A.T. Smith, H. He, D. O'Hare, L. Sun, Functionalized layered double hydroxides for innovative applications, Materials Horizons, 7, 715-745 (2020). Hydroxide (LDH) Modified Diatoms for Highly Efficient Removal of Congo Red from Aqueous Solution, Applied Sciences, 10, 2285 (2020).

480 [29] N. Asses, L. Ayed, N. Hkiri, M. Hamdi, Congo red decolorization and detoxification by Aspergillus niger: removal mechanisms and dye degradation pathway, BioMed research international, 2018 (2018).

[30] A. Tkaczyk, K. Mitrowska, A. Posyniak, Synthetic organic dyes as contaminants of the aquatic environment and their implications for ecosystems: A review, Science of The Total Environment, $717,137222(2020)$.

486 [31] Y. Zhou, J. Lu, Y. Zhou, Y. Liu, Recent advances for dyes removal using novel adsorbents: a 487 review, Environmental pollution, 252, 352-365 (2019). 
[32] T. Ngulube, J.R. Gumbo, V. Masindi, A. Maity, An update on synthetic dyes adsorption onto clay based minerals: A state-of-art review, Journal of environmental management, 191 (2017) 35-57.

[33] V. Gupta, Application of low-cost adsorbents for dye removal-a review, Journal of environmental management, 90, 2313-2342 (2009).

[34] H. Yi, S. Zhao, X. Tang, P. Ning, H. Wang, D. He, Influence of calcination temperature on the hydrolysis of carbonyl sulfide over hydrotalcite-derived $\mathrm{Zn}-\mathrm{Ni}-\mathrm{Al}$ catalyst, Catalysis Communications, 12, 1492-1495 (2011).

[35] R. Lafi, K. Charradi, M.A. Djebbi, A.B.H. Amara, A. Hafiane, Adsorption study of Congo red dye from aqueous solution to $\mathrm{Mg}$-Al-layered double hydroxide, Advanced Powder Technology, 27, 232-237 (2016).

[36] S. Wang, X. Yang, F. Wang, Z. Song, H. Dong, L. Cui, Effect of Modified Hydrotalcites on Flame Retardancy and Physical Properties of Paper, BioResources, 14, 3991-4005 (2019).

[37] Y. Shi, F. Chen, J. Yang, M. Zhong, Crystallinity and thermal stability of LDH/polypropylene nanocomposites, Applied Clay Science, 50, 87-91 (2010).

[38] G. Geng, R. Wei, T. Liang, M. Zhou, G. Xiao, Hydrogenolysis of glycerol to propanediols on $\mathrm{Cu}-\mathrm{Ca}-\mathrm{Al}$ hydrotalcites derived catalysts, Reaction Kinetics, Mechanisms and Catalysis, 117, 239251 (2016).

[39] J. Ashok, Y. Kathiraser, M. Ang, S. Kawi, Bi-functional hydrotalcite-derived $\mathrm{NiO}-\mathrm{CaO}-\mathrm{Al}_{2} \mathrm{O}_{3}$ catalysts for steam reforming of biomass and/or tar model compound at low steam-to-carbon conditions, Applied Catalysis B: Environmental, 172, 116-128 (2015).

[40] P.H. Chang, Y.P. Chang, S.Y. Chen, C.T. Yu, Y.P. Chyou, Ca-rich Ca-Al-oxide, hightemperature-stable sorbents prepared from hydrotalcite precursors: synthesis, characterization, and $\mathrm{CO}_{2}$ capture capacity, ChemSusChem, 4, 1844-1851 (2011).

[41] J. Pal, M.K. Deb, Efficient adsorption of congo red dye from aqueous solution using green synthesized coinage nanoparticles coated activated carbon beads, Applied Nanoscience, 4, 967-978 (2014). 
514 [42] M.O. Ansari, R. Kumar, S.A. Ansari, S.P. Ansari, M. Barakat, A. Alshahrie, M.H. Cho, Anion

515 selective pTSA doped polyaniline@graphene oxide-multiwalled carbon nanotube composite for $\mathrm{Cr}$

516 (VI) and Congo red adsorption, Journal of colloid and interface science, 496, 407-415 (2017).

517 [43] K.G. Bhattacharyya, A. Sharma, Azadirachta indica leaf powder as an effective biosorbent for

518 dyes: a case study with aqueous Congo Red solutions, Journal of Environmental Management, 71, $519 \quad 217-229(2004)$.

520 [44] R. Rahimi, H. Kerdari, M. Rabbani, M. Shafiee, Synthesis, characterization and adsorbing 521 properties of hollow $\mathrm{Zn}-\mathrm{Fe}_{2} \mathrm{O}_{4}$ nanospheres on removal of Congo red from aqueous solution, 522 Desalination, 280, 412-418 (2011).

523 [45] Y. Fu, T. Viraraghavan, Removal of Congo Red from an aqueous solution by fungus Aspergillus 524 niger, Advances in Environmental Research, 7, 239-247 (2002).

525

526

527

528

529

530

531

532

533

534

535

536 


\section{Figures caption}

538 Fig. 1. The FT-IR spectra of the prepared Cu-Ca-Al-LDH and LDH-ITA.

539 Fig. 2. The XRD patterns (a) and the TGA thermograms (b) of the prepared Cu-Ca-Al-LDH 540 and LDH-ITA.

541 Fig. 3. The scanning electron micrographs of the prepared $\mathrm{Cu}-\mathrm{Ca}-\mathrm{Al}-\mathrm{LDH}(\mathrm{a}-\mathrm{c})$ and LDH542 ITA (d-f) with different magnifications.

543 Fig. 4. The $\mathrm{N}_{2}$ adsorption/desorption isotherms of $\mathrm{Cu}-\mathrm{Ca}-\mathrm{Al}-\mathrm{LDH}$ (a), LDH-ITA (b), and the 544 BJH pore size distribution curves of the samples (c).

545 Fig. 5. The effect of $\mathrm{pH}(\mathrm{a})$, adsorbent amount (b), and contact time (c) on the adsorption of 546 Congo red by the prepared adsorbents.

547 Fig. 6. The kinetic adsorption models of pseudo-first-order (PFO), pseudo-second-order 548 (PSO), Elovich, and intra-particle diffusion (IPD) for adsorption of Congo red by the 549 prepared adsorbents.

550 Fig. 7. The equilibrium isotherm (a) and the isotherm models of Langmuir (b), Freundlich

551 (c), and Dubinin-Radushkevich (d) for adsorption of Congo red by the prepared adsorbents. 


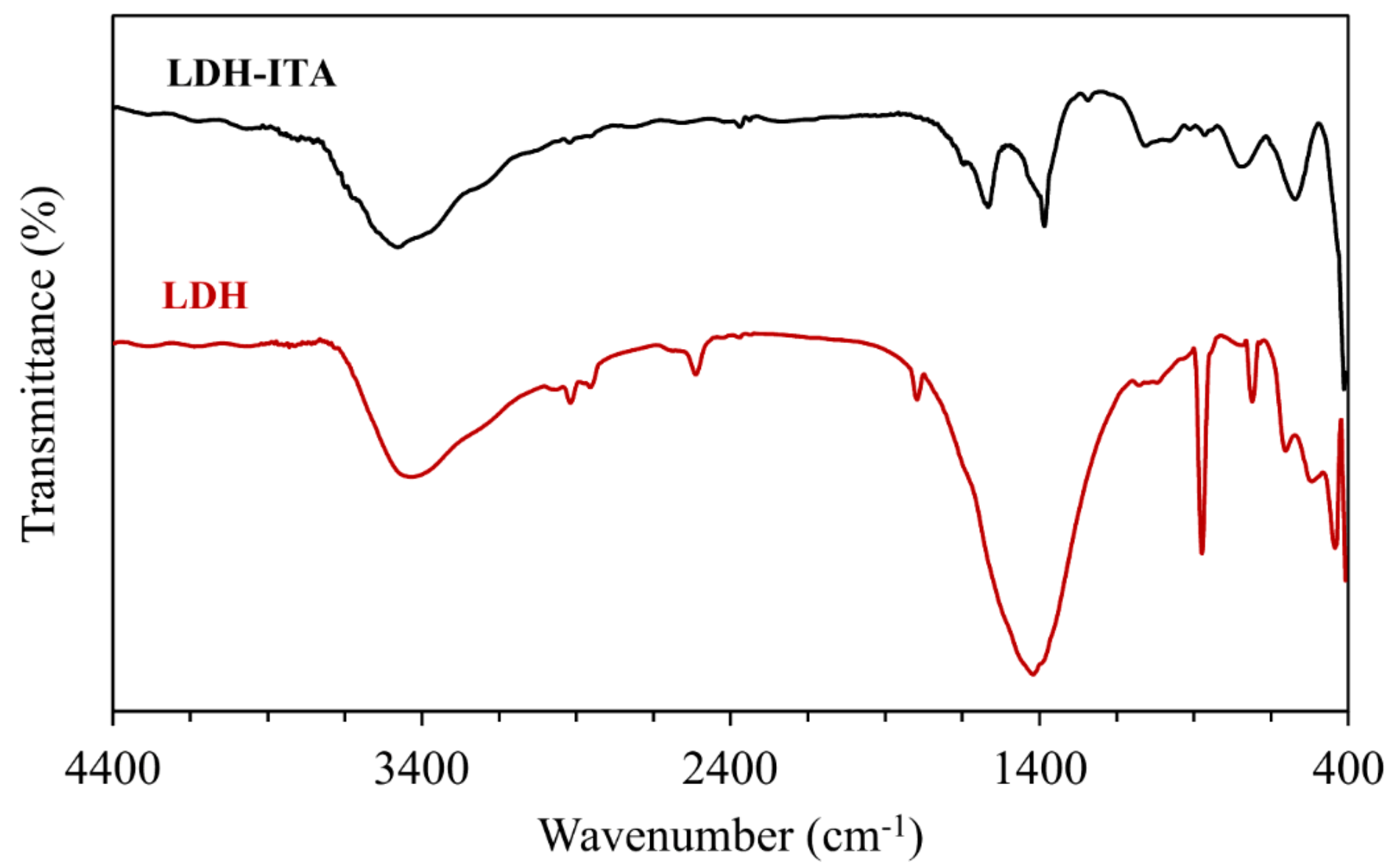

Figure 1

FT-IR spectra of the Cu-Ca-Al-LDH and LDH-ITA.

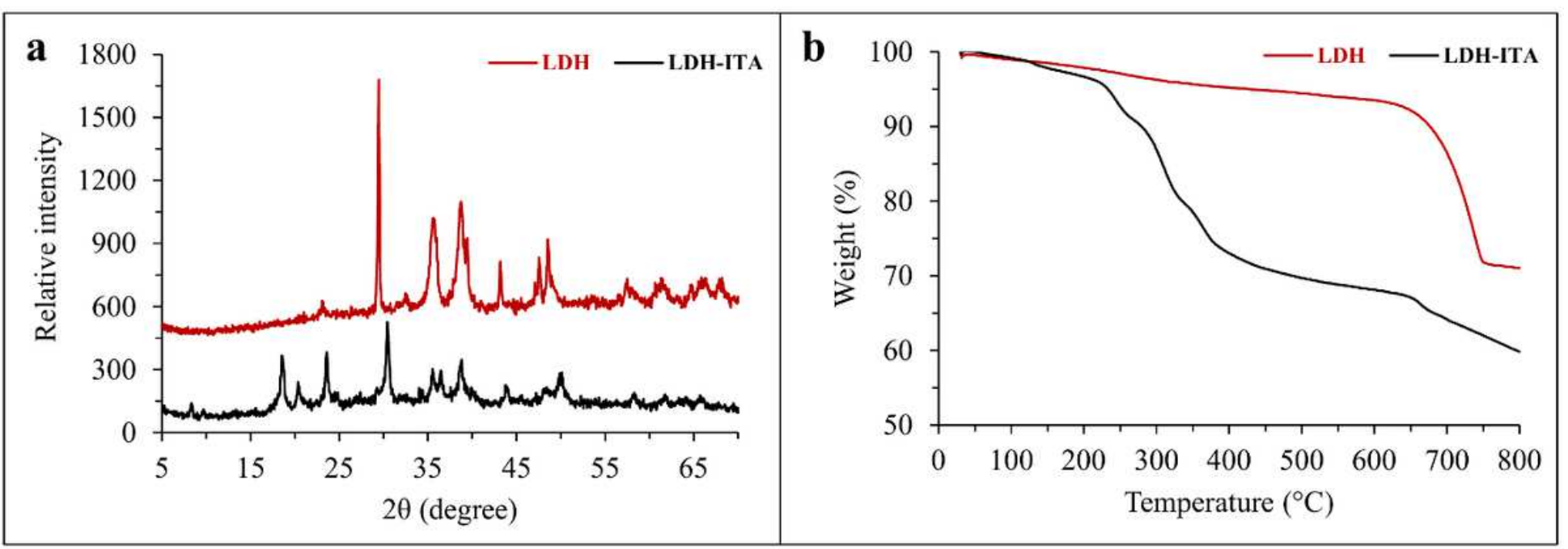

Figure 2

The XRD patterns (a) and the TGA thermograms (b) of the prepared Cu-Ca-Al-LDH and LDH-ITA. 


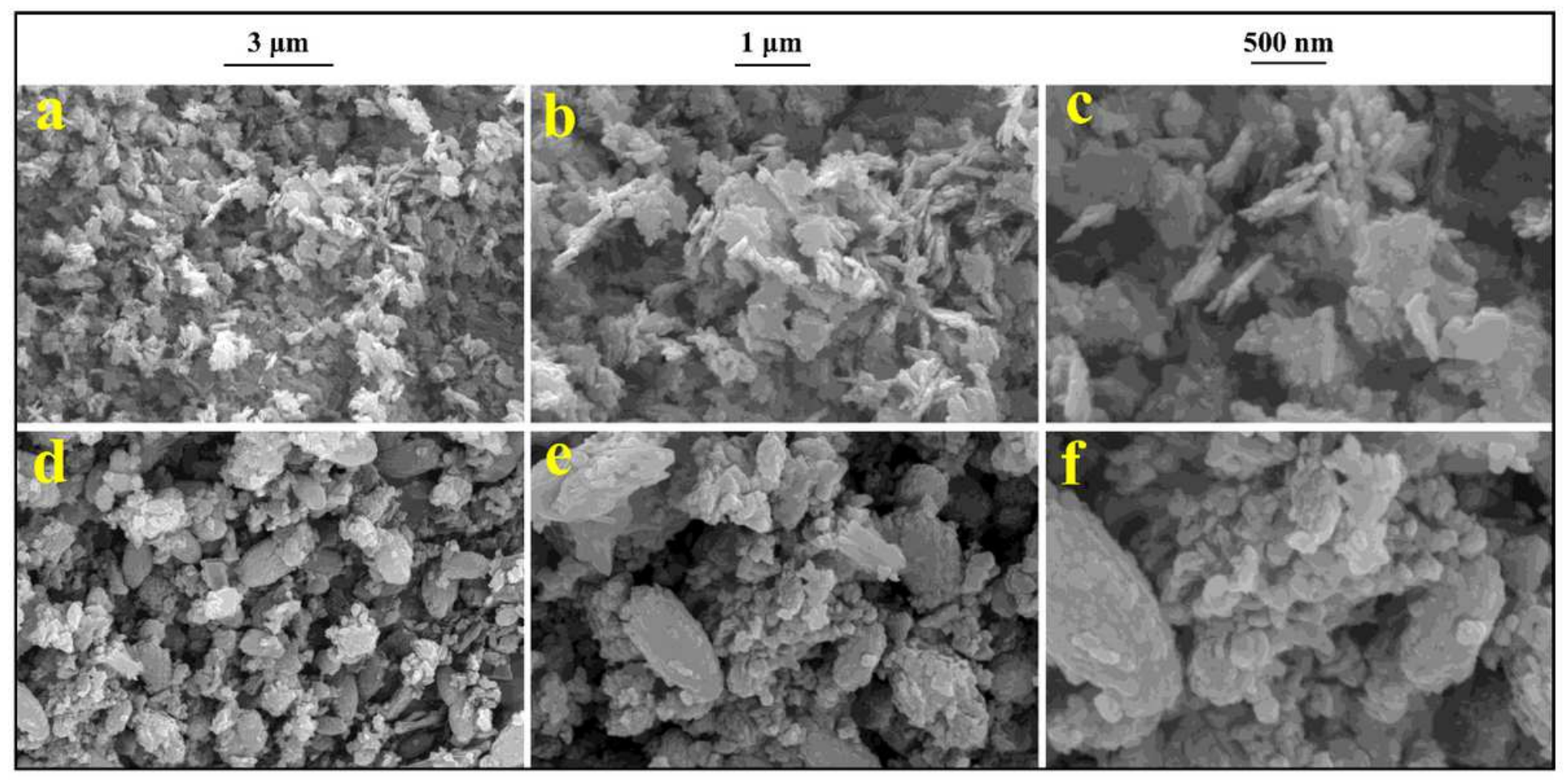

\section{Figure 3}

The scanning electron micrographs of the prepared Cu-Ca-Al-LDH (a-c) and LDH-ITA (d-f) with different magnifications.

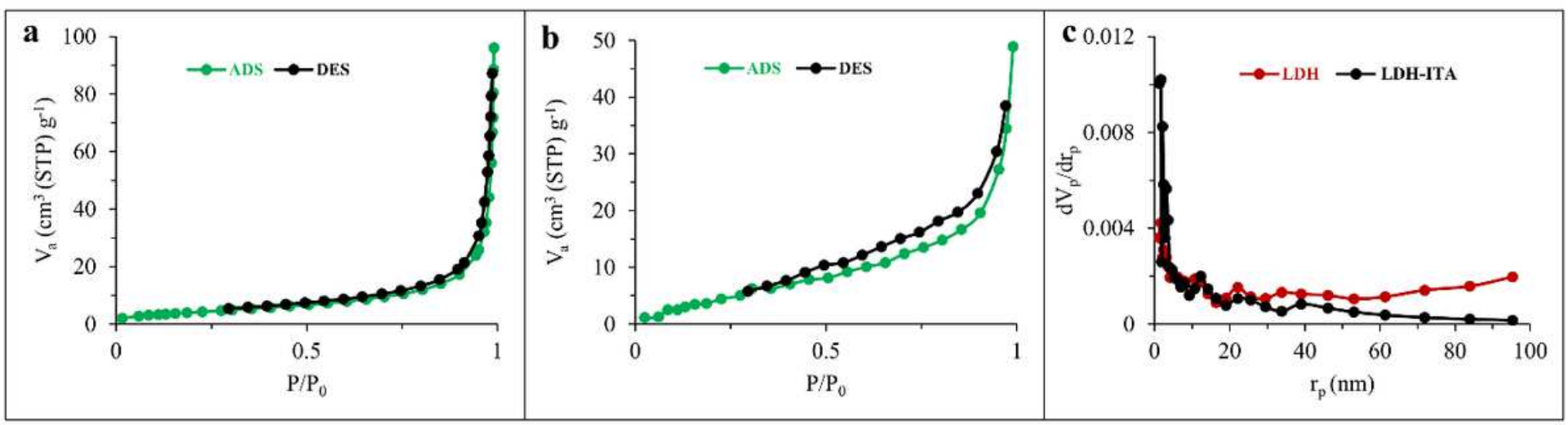

Figure 4

The N2 adsorption/desorption isotherms of Cu-Ca-Al-LDH (a), LDH-ITA (b), and the BJH pore size distribution curves of the samples (c). 

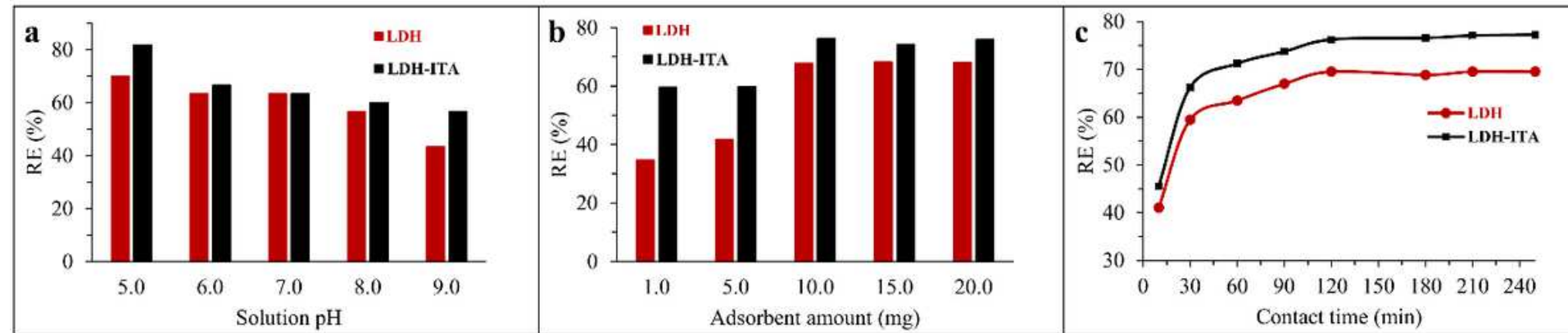

Figure 5

The effect of $\mathrm{pH}(\mathrm{a})$, adsorbent amount (b), and contact time (c) on the adsorption of Congo red by the prepared adsorbents.

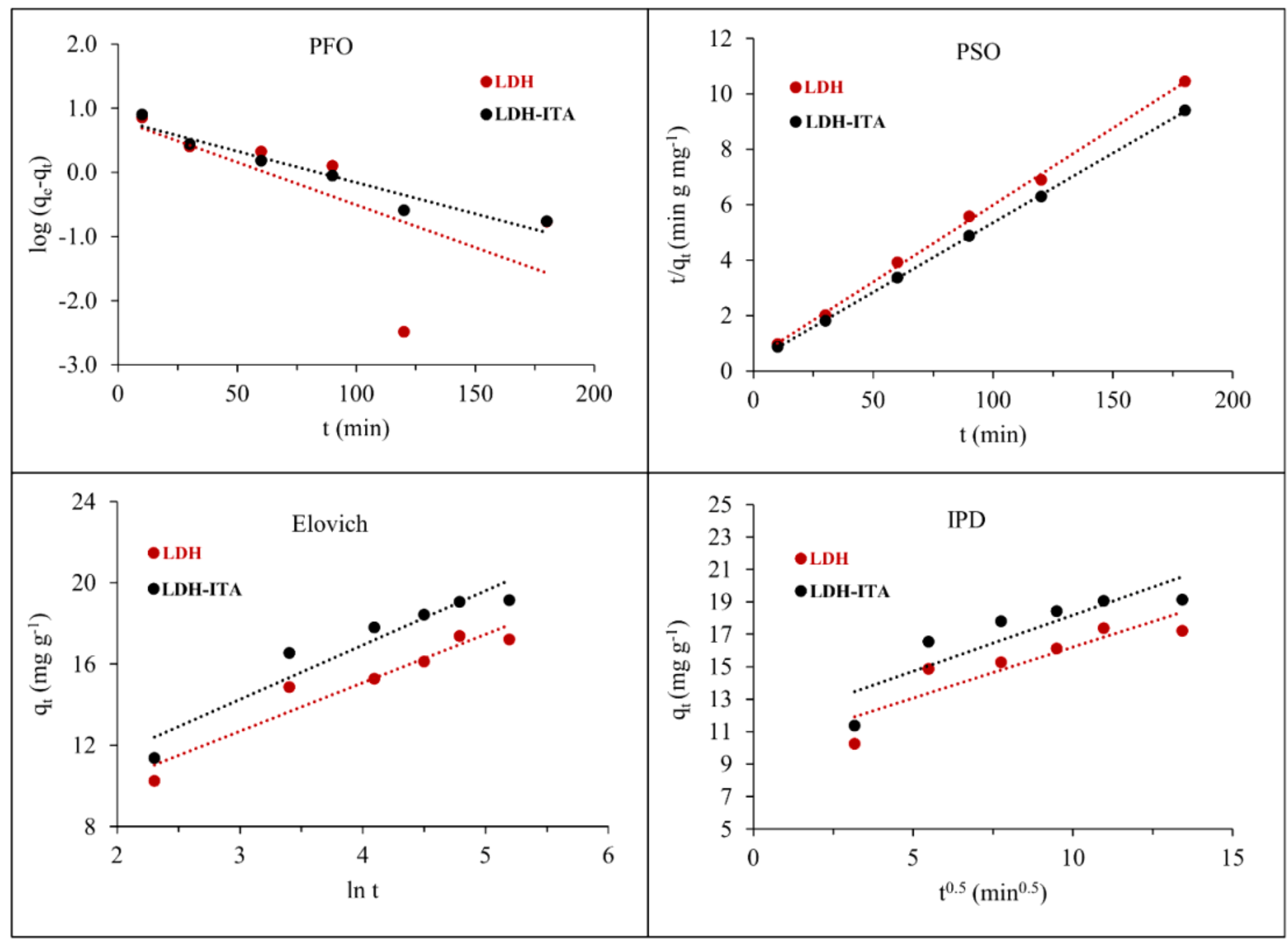

Figure 6

The kinetic adsorption models of pseudo-first-order (PFO), pseudo-second-order (PSO), Elovich, and intraparticle diffusion (IPD) for adsorption of Congo red by the prepared adsorbents. 


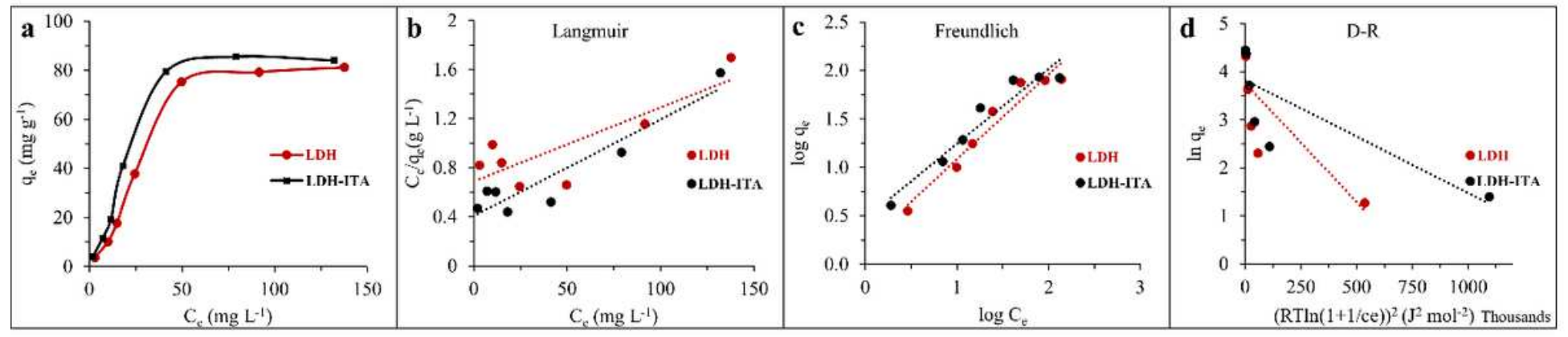

Figure 7

The equilibrium isotherm (a) and the isotherm models of Langmuir (b), Freundlich (c), and DubininRadushkevich (d) for adsorption of Congo red by the prepared adsorbents.

\section{Supplementary Files}

This is a list of supplementary files associated with this preprint. Click to download.

- Scheme1.png 